\begin{tabular}{|c|c|c|}
\hline Case Reports in & \multicolumn{2}{|c|}{ Case Rep Gastroenterol 2015;9:25-28 } \\
\hline Gastroenterology & $\begin{array}{l}\text { DOI: 10.1159/000369965 } \\
\text { Publisned online: January 24, } 2015\end{array}$ & $\begin{array}{l}\text { (c) } 2015 \text { S. Karger AG, Basel } \\
1662-0631 / 15 / 0091-0025 \$ 39.50 / 0 \\
\text { www.karger.com/crg }\end{array}$ \\
\hline & \multicolumn{2}{|c|}{$\begin{array}{l}\text { This is an Open Access article licensed under the terms of the Creative Commons } \\
\text { Attribution-NonCommercial } 3.0 \text { Unported license (CC BY-NC) (www.karger.com/OA- } \\
\text { license), applicable to the online version of the article only. Distribution permitted for non- } \\
\text { commercial purposes only. }\end{array}$} \\
\hline
\end{tabular}

\title{
Treatment of Refractory Crohn's Disease and Pyoderma Gangrenosum with a Combination Regimen of Rifaximin, Gentamicin and Metronidazole
}

\author{
Neil D. Goldberg ${ }^{a} \quad$ Aravinda Vadlamudi $^{b}$ Nicole Parrish $^{b}$ \\ ${ }^{a}$ St. Joseph Medical Center, The University of Maryland, Towson, Md., and \\ ${ }^{\mathrm{b}}$ The Johns Hopkins Medical Institutions, Baltimore, Md., USA
}

\section{Key Words}

Crohn's disease $\cdot$ Pyoderma gangrenosum $\cdot$ Combination therapy

\begin{abstract}
The etiology of Crohn's disease (CD) remains controversial. It is hypothesized that $C D$ is the result of an abnormal immune response to the gut flora in genetically susceptible hosts. However, an infectious etiology has not been completely ruled out. Antibiotics have been utilized with some success to modify the course of the disease. Here, we report a patient with $C D$ and pyoderma gangrenosum refractory to standard therapy, including biologics, who achieved remission with a combination of rifaximin, gentamicin and metronidazole.
\end{abstract}

(c) 2015 S. Karger AG, Basel

\section{Introduction}

The etiology of Crohn's disease (CD) continues to stir debate. Currently, it is hypothesized that CD is caused by an abnormal immune response to the gut flora in genetically susceptible hosts. This hypothesis is supported by the fact that CD (and ulcerative colitis) patients have a distinct intestinal microbiota compared to controls [1]. On the other hand, multiple studies have been conducted utilizing various antimicrobial drugs alone and in combination for the treatment of CD [2-4]. For instance, rifaximin has shown some promise in

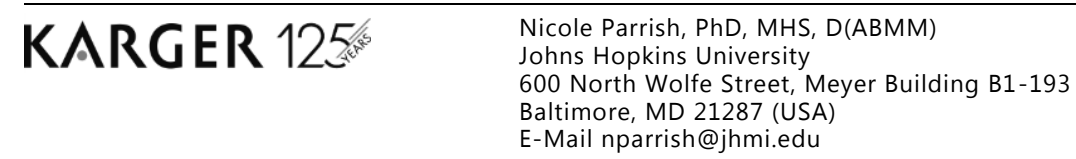


Goldberg et al.: Treatment of Refractory CD and Pyoderma Gangrenosum with a Combination Regimen of Rifaximin, Gentamicin and Metronidazole

inducing remission in $\mathrm{CD}$ and metronidazole has been used to prevent relapse following surgery [5]. Combination regimens have also been tested, including those which paired a macrolide such as clarithromycin with other antimycobacterial drugs (rifabutin, ciprofloxacin, clofazimine and ethambutol) [2]. Other antibiotic classes such as the aminoglycosides have not been used for the treatment of CD. However, several drugs in this class are known to have potent antimycobacterial activity against numerous mycobacterial species including Mycobacterium tuberculosis (MTB) and the Mycobacterium avium complex both in vitro and in vivo $[6,7]$. Recently, we demonstrated synergy in vitro between gentamicin and rifaximin against control and clinically derived strains of M. avium subspecies paratuberculosis (MAP), which has been suggested may play a role in CD but has yet to be definitively established. Here we report a case of CD complicated by pyoderma gangrenosum refractory to standard therapy treated successfully with a combination of rifaximin, gentamicin and metronidazole.

\section{Case Report}

A 44-year-old Caucasian female presented with a 10-year history of biopsy-proven CD involving the terminal ileum and a 3-year history of pyoderma gangrenosum. Upon presentation, she was treated with thalidomide for 3 months without change. The patient's pyoderma was then treated with Remicade $(10 \mathrm{mg} / \mathrm{kg})$, resulting in only partial benefit. Subsequently, treatment was switched from Remicade to Humira in April 2012. After an induction dose, she remained on $40 \mathrm{mg}$ administered subcutaneously every 2 weeks. Despite this, she presented on July 15, 2013 with painful, ulcerated lesions on the lower extremity (fig. 1a). She also complained of right lower quadrant discomfort. There were no fevers, chills or rigor. There was no blood per rectum, diarrhea, nausea, vomiting or weight loss. Physical examination was remarkable for mild right lower quadrant tenderness without mass, guarding or rebound tenderness. Her white blood cell count was 7,100/ $\mathrm{mm}^{3}$, hematocrit $32.9 \%$ and hemoglobin $11.2 \mathrm{~g} / \mathrm{dl}$. Her comprehensive metabolic panel was completely normal and her sedimentation rate was $37 \mathrm{~mm} / \mathrm{h}$. Her other medications included Delzicol (3,600 mg daily), vitamin B12 (1 mg intramuscularly monthly), vitamin D (50,000 units per month), omeprazole (20 mg daily) and a probiotic twice a day. The patient was treated three times a day with a combination of gentamicin (80 mg), rifaximin (550 mg) and metronidazole (250 $\mathrm{mg}$ ). Within 1 week, the patient's pyoderma was arrested with no new skin lesions and her right lower quadrant abdominal pain resolved. After 4 weeks, no active skin lesions remained (fig. 1b). The patient also underwent follow-up colonoscopy after 3 months of the triple antibiotic therapy. No evidence of disease was present including $20 \mathrm{~cm}$ of the distal ileum.

\section{Discussion}

Although an infectious etiology, mycobacterial or otherwise, has not been definitely established for CD or pyoderma gangrenosum, treating MAP was the theoretical basis for this regimen and our patient experienced dramatic remission with the combination of rifaximin, gentamicin and metronidazole. Rifaximin and metronidazole have both been used in prior studies for the treatment of CD [2]. Rifaximin has been associated with remission in some CD patients, and metronidazole has demonstrated some efficacy for prevention of relapse following surgery [5]. Other antimycobacterial drugs such as rifabutin, ciprofloxacin, clofazimine and ethambutol have also been used alone and in limited combination for the treat- 
Goldberg et al.: Treatment of Refractory CD and Pyoderma Gangrenosum with a Combination Regimen of Rifaximin, Gentamicin and Metronidazole

ment of CD with varying degrees of efficacy [2]. However, to date no regimen has resulted in a permanent cure of $C D$.

Other antibiotic classes, such as the aminoglycosides, have yet to be tested for the treatment of CD. Several drugs in this class are known to have potent antimycobacterial activity against numerous mycobacterial species, including MTB and the M. avium complex in vivo, and MAP in vitro [6, 7]. MAP is known to cause Johne's disease in ruminants. However, its role in $\mathrm{CD}$ is controversial. Recent studies conducted in our laboratory revealed that MAP is capable of both aerobic growth and adaptation to anaerobiosis when using an in vitro model developed for MTB [8-10]. This model shows the progression of MTB through two stages of non-replicating persistence (NRP) in response to the gradual withdrawal of oxygen and the resulting differential susceptibility to antimicrobial agents $[8,9]$. Importantly, antibiotics active against aerobically growing bacilli, such as isoniazid and rifampin, have no activity against NRP-adapted bacilli, which are only susceptible to metronidazole. Using this in vitro model, not only was MAP able to adapt to anaerobic conditions and establish NRP as demonstrated with MTB, but also exhibited differential susceptibility to various antibiotics when grown under aerobic versus anaerobic conditions. As a result, one could speculate that MAP may exist in the gut in both an aerobic and an NRP-adapted state. Should this be the case, eradication of both MAP populations would require combinations of antimicrobials which include both aerobically and anaerobically active agents such as rifaximin, gentamicin and metronidazole. In this particular patient, it is not known whether MAP was present, therefore the dramatic remission may have been due to alteration of the microbiome of the gut rather than specific eradication of a specific organism. Since rifaximin and gentamicin are not absorbed from the intestine, concentrations of each drug would have been localized within the gut, which in combination with metronidazole may have contributed to the overall improvement observed in this patient. Regardless, the dramatic remission demonstrated in this patient suggest that a controlled clinical trial with this combination may be worthwhile in patients who do not respond to conventional therapy.

\section{References}

1 Baker PI, Love DR, Ferguson LR: Role of gut microbiota in Crohn's disease. Expert Rev Gastroenterol Hepatol 2009;3:535-546.

-2 Feller M, Huwiler K, Schoepfer A, Shang A, Furrer H, Egger M: Long-term antibiotic treatment for Crohn's disease: systematic review and meta-analysis of placebo-controlled trials. Clin Infect Dis 2010;50:473-480.

3 Borgaonkar MR, MacIntosh DG, Fardy JM: A meta-analysis of antimycobacterial therapy for Crohn's disease. Am J Gastroenterol 2000;95:725-729.

-4 Borody TJ, Leis S, Warren EF, Surace R: Treatment of severe Crohn's disease using antimycobacterial triple therapy - approaching a cure? Dig Liver Dis 2002;34:29-38.

5 Scribano ML, Prantera C: Use of antibiotics in the treatment of Crohn's disease. World J Gastroenterol 2013;19:648-653.

-6 Heifets LB, Lindholm-Levy PJ, Comstock RD: Bacteriostatic and bactericidal activities of gentamicin alone and in combination with clarithromycin against Mycobacterium avium. Antimicrob Agents Chemother 1992;36:1695-1698.

7 Parrish NM, Ko CG, Dick JD, Jones PB, Ellingson JL: Growth, Congo Red agar colony morphotypes and antibiotic susceptibility testing of Mycobacterium avium subspecies paratuberculosis. Clin Med Res 2004;2: 107-114.

8 Wayne LG, Hayes LG: An in vitro model for sequential study of shiftdown of Mycobacterium tuberculosis through two stages of nonreplicating persistence. Infect Immun 1996;64:2062-2069.

-9 Lim A, Eleuterio M, Hutter B, Murugasu-Oei B, Dick T: Oxygen depletion induced dormancy in Mycobacterium bovis BCG. J Bacteriol 1999;181:2252-2256.

10 Parrish N, Ko C, Dick J: Growth and antibiotic susceptibility of Mycobacterium avium subspecies paratuberculosis under aerobic and anaerobic conditions. 107th American Society for Microbiology General Meeting, Toronto, Canada, 2007. 


\begin{tabular}{rl|l} 
Case Reports in & \multicolumn{2}{l}{} \\
\cline { 2 - 3 } Gastroenterology & DOI: 10.1159/000369965 & $\begin{array}{l}\text { ○ 2015 S. Karger AG, Basel } \\
\text { www.karger.com/crg }\end{array}$ \\
\cline { 2 - 3 }
\end{tabular}

Goldberg et al.: Treatment of Refractory CD and Pyoderma Gangrenosum with a Combination Regimen of Rifaximin, Gentamicin and Metronidazole
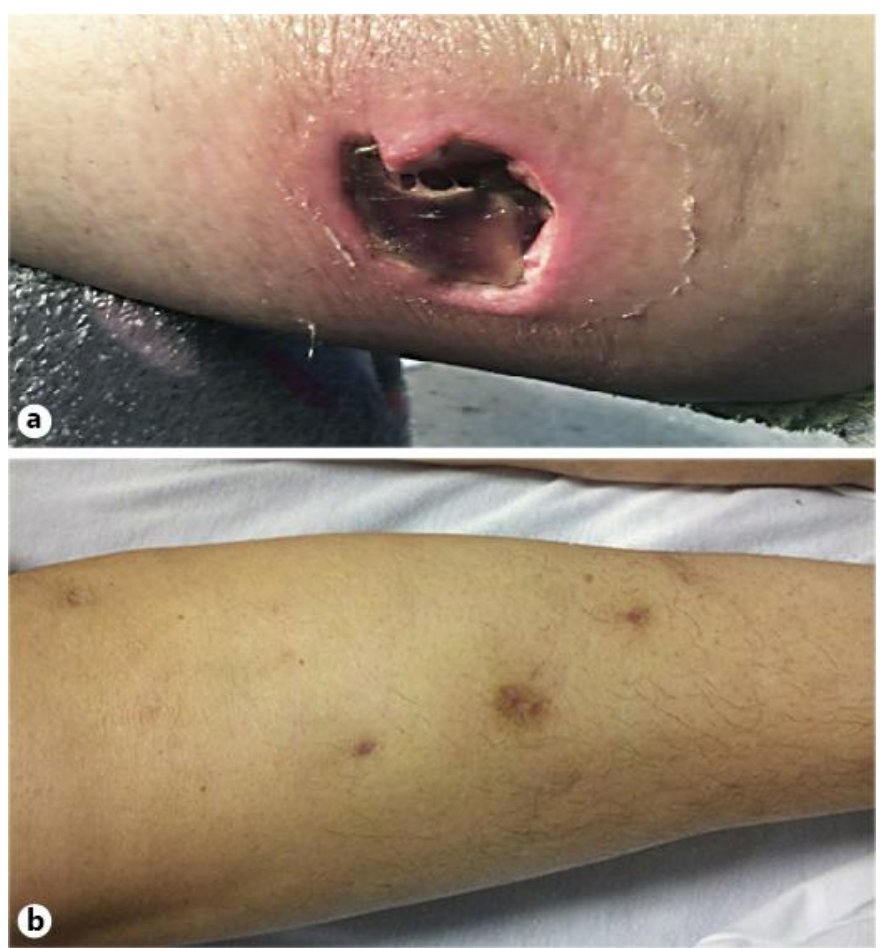

Fig. 1. a The left shin showing ulcerated lesions prior to initiation of triple combination therapy with rifaximin, gentamicin and metronidazole. $\mathbf{b}$ The left shin showing completely healed lesions after 4 weeks of triple combination therapy with rifaximin, gentamicin and metronidazole. 